\title{
Title: Increased risk of mortality after postoperative infection in hip fracture patients
}

\section{Authors:}

Kaja Eriksrud Kjørholt ${ }^{1}$, Nickolaj Risbo Kristensen ${ }^{1}$, Daniel Prieto-Alhambra ${ }^{2}$, Søren Paaske Johnsen ${ }^{1,3}$, Alma Bečić Pedersen ${ }^{1}$

\section{Affiliations:}

${ }^{1}$ Department of Clinical Epidemiology, Aarhus University Hospital, Aarhus, Denmark.

Address: Olof Palmes Allé 43-45, 8200 Aarhus N, Denmark.

${ }^{2}$ Centre for Statistics in Medicine, Nuffield Department of Orthopaedics, Rheumatology, and

Musculoskeletal Sciences (NDORMS) University of Oxford, Oxford, United Kingdom

Address: Old Rd, Oxford OX3 7LD, United Kingdom.

${ }^{3}$ Danish Center for Clinical Health Services Research, Department of Clinical Medicine, Aalborg University, Aalborg, Denmark.

Address: Mølleparkvej 10, 9000 Aalborg, Denmark.

\section{Corresponding author:}

Kaja E. Kjørholt, Department of Clinical Epidemiology, Aarhus University Hospital, Olof Palmes Allé 43-45, 8200 Aarhus N, Denmark. E-mail: kaja.eriksrud.kjoerholt@gmail.com

Telephone: +45- 50581862 Fax: +45- 87167215 


\section{Abstract (263 words)}

Background: Postoperative infection is a common complication in hip fracture patients and the risk appears to have increased during the last decade. However, the impact of infection on mortality after hip fracture surgery remains unclear. Purpose: We aimed to examine the association between infection (any, as well as specific infections), with all-cause mortality following hip fracture surgery. Methods: Using Danish nationwide registries, we conducted a population-based cohort study on 74,771 hip fracture patients $\geq 65$ years old operated from $2005-2016$. We included hospital-treated infection as a time-varying exposure, and calculated 30-days mortality rate per 1000 person-years (PY). We used time-varying Cox Proportional Hazard Regression to compute 30-days adjusted hazards ratios (aHRs) with $95 \%$ confidence interval (CI) comparing the mortality of hip fracture patients with and without infections. We adjusted for sex, age, comorbidities, medication use, and marital status. Results: Within 30 days of surgery, 9,592 (12.8\%) patients developed a hospital-treated infection. Among these, 30-days mortality was 8.43 per $1000 \mathrm{PY}$ compared with 3.34 among patients without infection (aHR=2.72, 95 \% CI: 2.56-2.88). For patients who developed pneumonia, aHR was 4.18 (95 \% CI: 3.91-4.48), whereas the aHR was 8.86 (95 \% CI: 7.88-9.95) for patients who developed systemic sepsis. For patients who sustained reoperation due to infection, aHR was 2.95 (95 \%CI: 1.88-4.64). The mortality was higher in infected vs. noninfected patients irrespective of patients' age, sex and comorbidity. Conclusion: Infection within 30 days of hip fracture surgery is associated with substantially increased mortality risk. Further research should improve our knowledge about patients at increased risk and prevention measures for specific infections.

Key words: Hip fracture surgery; Postoperative infection; Mortality; Epidemiology 


\section{Introduction}

Hip fracture is a frequent condition among elderly, and is associated with high morbidity and mortality.[1, 2] Approximately $10 \%$ dies within 30 days after surgery, and up to $30 \%$ dies within 1 year after surgery.[2-4] The high mortality could be attributed to comorbidities already present at the time of fracture,[5] but may also be due to postoperative complications.[6, 7] Postoperative infection is a common complication in hip fracture patients, and pneumonia is previous reported as the most frequent postoperative complication at one hospital in England (9\%).[3] The 30-days risk of postoperative hospital-treated infection was recently reported to be $14.1 \%$ among Danish hip fracture patients, increasing by 32\% from 2005-2016.[8]

Furthermore, postoperative infection has been reported to be among the leading causes of death among hip fracture patients.[9] However, the impact of infections on all-cause mortality after hip fracture surgery is not clear. Previous research has shown that the 30-days mortality after hip fracture surgery is $27-43 \%$ following pneumonia,[3, 10, 11] $21 \%$ following sepsis,[12] and $19 \%$ following deep infection.[13] However, to the best of our knowledge, no previous studies have evaluated the mortality risk after any infection or used a population-based design. Furthermore, neither of the studies considered immortal time bias in their relative risk analysis, which could potentially underestimate mortality risk among infected patients [14, 15]. If we classified the patients in infected or not-infected group for example within 30 days of follow up, the immortal time refers to a period of follow-up during which, by design, death cannot occur, thus, infected patients have to survive to be included in infected group Finally, the majority of previous studies are from United States and Asia, where the general burden of infections and treatment may differ from that in Europe and the Nordic countries. ${ }^{1}$

\footnotetext{
Abbrevations: CRS: Civil Registration System, DMHFR: The Danish Multidisciplinary Hip Fracture Registry, DNPR: The Danish National Patient Registry, DNHSPD: The Danish National Health Service Prescription Database , PPV: Positive Predictive Value, GP: General Practitioners, PY: Person-Years
} 
Due to the increasing burden of infections and use of antibiotics,[8] as well as risk of developing multidrug resistance bacteria,[16] it is highly important to illuminate the impact of infections on the mortality after hip fracture surgery. Identification of specific infections and patients who are at increased risk of mortality could guide treatment and potentially reduce mortality of hip fracture patients.

We used a large nationwide cohort study to examine the association between infection and all-cause mortality following hip fracture surgery. Additionally, we assessed the relationship between specific types of infection (pneumonia, systemic sepsis, and reoperation due to infection), and allcause mortality.

\section{Methods}

\section{$\underline{2.1 \text { Setting and design }}$}

We designed a nationwide cohort study, based on prospectively collected patient-level data from Danish medical databases. Every Danish citizen ( $n=5,711,870$ in 2016) receives tax-supported health care, including free access to hospitals, general practitioners, and outpatient clinics. The Danish Civil Registration System (CRS) assigns a unique, personal identifier number used by all Danish registries, working as a tool for individual-level linkage between registries.[17] This study is based on data linkage between CRS, Danish Multidiciplinary Hip Fracture Registry (DMHFR),[18] The Danish National Patient Registry (DNPR),[19] and The Danish National Health Service Prescription Database (DNHSPD).[20]

\section{$\underline{2.2 \text { Study population }}$}

Using the DMHFR, which is a nationwide clinical-quality database, we identified all patients $\geq 65$ years old with surgically treated medial, pertrochanteric or subtrochanteric femoral hip fracture between January 1, 2005 to December 31, 2016 in Denmark.[18] Reporting to DMHFR is 
mandatory for every Danish hospital executing hip fracture surgery, and it contains prospectively collected pre-, per- and post- operative individual-level data.

We included patients with a record of either a primary or a secondary hip fracture diagnosis during the study period. To be eligible, patients had to have an inpatient hospital admission for their fracture and operative treatment including insertion of a primary hip replacement or open reduction and internal fixation. Patients identified only on an outpatient basis or in the emergency room were not included.

\subsection{Infection}

We obtained information on hospital-treated infections from the DNPR which has registered hospital admissions since 1977 and outpatient and emergency visits since 1995.[19] Detailed description of DNPR has previously been published.[19] We defined hospital-treated infection as any first-time hospital admission or outpatient clinic visit with a primary or secondary infection diagnosis at a private or a public hospital, after the hip fracture surgery date. Additionally, we divided any infection into specific groups of infections, including pneumonia, systemic sepsis, and reoperation due to infection. We further explored the risk of urinary track infection. In order to avoid immortal time bias, we defined infection as time-varying exposure.[14, 15] Thus, the patients were classified as unexposed from the date of surgery up until the exact day of infection, and then classified as exposed throughout the rest of the follow-up period. Hence, the index date for all patients was defined as the date of hip fracture surgery, whereas infected patients contributed to the unexposed group initially (from hip fracture surgery) but were then moved to the exposed group from the day of infection, which became their index date (See Supplementary Figure 1). Patients with a hospital-treated infection between 0-30 days after index date were eligible in our analysis. The patients are immortal in the time between hip fracture surgery and up to the exact day of 
infection (because they cannot die if they will develop an infection later on), and in reality still unexposed, because they not have developed an infection yet. [14, 15] If we instead followed every patient from the date of surgery and defined exposure as infection within 30 days (binary; yes or no), this would lead to misclassified immortal time. Hence, the exposed group would include immortal person-time that instead belonged to the unexposed group, potentially leading to bias downwards.

\section{$\underline{2.4 \text { Mortality }}$}

The study outcome was all-cause mortality, obtained from the Danish CRS. The CRS was established in 1968 and contains electronic records on vital status (date of death or emigration) for the entire Danish population and is updated daily.[17] We examined short-term mortality, defined as the risk of dying 0-30 days after the index date. We focused on 30-days mortality in order to stress postoperative and hip fracture related infection.

\subsection{Covariates}

Patient characteristics, including sex, age (65-74, 75-84, and $\geq 85$ ), fracture type (femoral neck, and per/subtrochanter fracture), operation type (total/hemi arthroplasty, and osteosynthesis), surgery delay (<24, 24-36, >36 hours, and unknown), operation year (2005-2006, 2007-2008, 2009-2010, 2011-2012, 2013-2014, and 2015-2016) and body mass index [BMI; weight in kilograms (kg) divided by the square of height in meters (m) $(<18.5 \mathrm{~kg} / \mathrm{m} 2,18.5-24.9 \mathrm{~kg} / \mathrm{m} 2,25-29.9 \mathrm{~kg} / \mathrm{m} 2$, and $\geq 30 \mathrm{~kg} / \mathrm{m} 2)$ ], were collected from DNHSPD at index date.

We obtained information on comorbidity from DNPR ten years prior to index date, and detected 19 major comorbidities included in Charlson Comorbidity Index (CCI) score.[21] We classified comorbidities by three different CCI-scores, low CCI (score 0 - no known comorbidities), medium 
CCI (score 1-2), and high CCI (score 3 or more). Presence of one or more alcohol-related comorbidities (not included in CCI) was included separately.

From the DNHSP, we collected data on medication: systemic corticosteroids, antibiotic use, oral anticoagulants, anti-osteoporotic medication, statins, non- steroidal anti-inflammatory drugs (NSAIDs), and selective serotonin reuptake Inhibitors (SSRIs). The DNHSP contains data on all dispensings from community pharmacies and hospital-based outpatient pharmacies in Denmark since 2004, coded according to the Anatomical Therapeutic Chemical classification system.[20] Current medication use was classified as at least one dispensing prescription within 90 days prior index date, and former medication use as prescription within 91-365 days prior index date. Marital status (married/unmarried) was included as a covariate of social conditions and detected from CRS (All codes for the study variables are available in Supplementary Table 1).

\section{$\underline{2.6 \text { Statistical analysis }}$}

We tabulated characteristics of the study population by infection status within 30 days after surgery (binary; yes or no). We followed patients from index date and up until death or end of follow-up (30 days after surgery date) in order to assess infection status as time-varying exposure and subsequently calculated 30-days mortality rates (MRs) for each group, as the numbers of deaths divided by the total of risk-time, expressed by 1,000 person-years. To evaluate the association between infection and mortality, we used time-varying Cox Proportional Hazard Regression to compute crude and multivariable-adjusted hazards ratios (HRs) with $95 \%$ confidence interval (CI). In our multivariable analysis, we adjusted for sex, age, CCI-score, alcohol-related comorbidities, current medication use (systemic corticosteroids, SSRI, oral anticoagulants, and antibiotics), and marital status. Furthermore, we stratified according to sex, age and CCI-score, while adjusting for the remaining covariates (only sex, age and CCI-score). Assumptions for proportional hazard were 
analyzed by log-minus-log plot, and accepted. Additionally, we performed a sensitivity analysis to examine potential residual confounding of comorbidity. We repeated the analysis adjusting for specific comorbidities (diabetes, dementia, moderate to severe kidney disease, liver disease, chronic pulmonary disease, congenital heart disease, any tumor and metastatic tumor) instead of using CCIscore.

All statistical analyses were conducted using Stata Version 15.0 (Stata Corp, College Station, Texas, USA).

\section{$\underline{2.7 \text { Ethical consideration }}$}

The study has been approved by the Danish Data Protection Agency (Jr.nr at Region of Central Denmark 1-16-02-467-15). Registry based studies do not require formal ethical approval according to Danish law.

\section{Results}

\subsection{Description of the study population}

Among 74,771 hip fracture patients, 9,592 (12.8\%) sustained infection within 30 days after surgery. Infected patients had higher levels of comorbidity, were more likely to use medication like SSRI, antibiotics, and oral anticoagulants' shortly before surgery, and were more often males, compared to non-infected patients (Table 1). Median age at the time of operation was 84 years in infected patients and 82 years in non-infected patients.

Figure 1A shows distribution of postoperative days when infection was diagnosed. The most frequent day of postoperative infection was day 1 after surgery, and median time to infection diagnosis was postoperative day 8. The exact day of death after postoperative infection is presented in Figure 1B. The median time to death after developing a postoperative infection was 6 days, but the most frequent day of dying after an infection was day 1 or day 2. The 4 specific groups of 
infections (Table 2) represent $95 \%$ of any infection. The remaining $5 \%$ infections includes various gastrointestinal infections, skin infections, abscess etc (See Supplemental Table 1 for a complete list of infections and codes representing any hospital-treated infection). 
Baseline characteristics of hip fracture cohort

Patient characteristics

Patients with infection

Patient without infection

Total

\begin{tabular}{|c|c|c|c|}
\hline No. of patients & 9,592 & 65,179 & 74,771 \\
\hline \multicolumn{4}{|l|}{ Gender } \\
\hline Female & 6,387 (67\%) & 46,959 (72\%) & $53,346(71 \%)$ \\
\hline Male & 3,205 (33\%) & $18,220(28 \%)$ & $21,425(29 \%)$ \\
\hline \multicolumn{4}{|l|}{ Age, years } \\
\hline Median age & 84 & 82 & 83 \\
\hline $65-74$ & $1,438(15 \%)$ & $12,964(20 \%)$ & $14,402(19 \%)$ \\
\hline 75-84 & 3,639 (38\%) & 25,102 (38\%) & $28,741(38 \%)$ \\
\hline$\geq 85$ & 4,515 (47\%) & $27,113(42 \%)$ & $31,628(42 \%)$ \\
\hline \multicolumn{4}{|l|}{ Charlson Comorbidity } \\
\hline \multicolumn{4}{|l|}{ Index score } \\
\hline - 0 (No comorbidity) & 3,133 (32\%) & 26,986 (41\%) & $30,099(40 \%)$ \\
\hline - 1-2 (Medium) & $4,102(43 \%)$ & $26,143(40 \%)$ & $30,245(40 \%)$ \\
\hline - 3+ (High) & $2,377(25 \%)$ & $12,050(18 \%)$ & 14,427 (19\%) \\
\hline \multicolumn{4}{|l|}{ Alcohol-related conditions* } \\
\hline None & 9,183 (96\%) & 62,951 (97\%) & 72,134 (96 \%) \\
\hline 1 or more & $409(4 \%)$ & 2,228 (3 \%) & $2,637(4 \%)$ \\
\hline \multicolumn{4}{|l|}{ Fracture type } \\
\hline Fracture of femoral neck & 4,817 (50\%) & $34,781(53 \%)$ & 39,598 (53 \%) \\
\hline $\begin{array}{l}\text { Per and Sub-trochanter } \\
\text { fractures }\end{array}$ & $4,775(50 \%)$ & $30,398(47 \%)$ & $35,173(47 \%)$ \\
\hline \multicolumn{4}{|l|}{ Operation type } \\
\hline Osteosyntheses & 6,556 (68) & 44,980 (69\%) & $51,536(69 \%)$ \\
\hline Total and hemi hip arthroplasty & 3,036 (32) & 20,199 (31\%) & 23,235 (31\%) \\
\hline \multicolumn{4}{|l|}{ Married status } \\
\hline Unmarried & 6,917 (72\%) & $45,760(70 \%)$ & $52,677(70 \%)$ \\
\hline Married & $2,675(28 \%)$ & $19,419(30 \%)$ & $22,094(30 \%)$ \\
\hline \multicolumn{4}{|l|}{ Medication use } \\
\hline \multicolumn{4}{|l|}{ Anti-Osteoporotic medication } \\
\hline -Former use & $293(3 \%)$ & $1,646(3 \%)$ & 1,939 (3\%) \\
\hline -Current use & $762(8 \%)$ & $4,758(7 \%)$ & $5,520(7 \%)$ \\
\hline \multicolumn{4}{|l|}{ Systemic corticosteroids } \\
\hline -Former use & 474 (5\%) & $2,730(4 \%)$ & $3,205(4 \%)$ \\
\hline -Current use & $760(8 \%)$ & $3,846(6 \%)$ & $4,606(6 \%)$ \\
\hline \multicolumn{4}{|l|}{ Statins } \\
\hline -Former use & $627(7 \%)$ & $5,061(6 \%)$ & 4,688 (6\%) \\
\hline
\end{tabular}




\begin{tabular}{|c|c|c|c|}
\hline -Current use & 1,826 (19\%) & $11,714(18 \%)$ & $13,540(18 \%)$ \\
\hline \multicolumn{4}{|l|}{ NSAID } \\
\hline -Former use & $958(10 \%)$ & $6,798(10 \%)$ & $7,756(10 \%)$ \\
\hline -Current use & $1,021(11 \%)$ & $7,684(12 \%)$ & $8,705(12 \%)$ \\
\hline \multicolumn{4}{|l|}{ SSRI } \\
\hline -Former use & $443(5 \%)$ & $2,575(4 \%)$ & $3,018(4 \%)$ \\
\hline -Current use & 1,995 (21\%) & 12,608 (19\%) & $14,603(20 \%)$ \\
\hline \multicolumn{4}{|l|}{ Oral Antikoagulantia } \\
\hline -Former use & 1,043 (11\%) & $6,317(10 \%)$ & $7,360(10 \%)$ \\
\hline -Current use & 4,146 (43\%) & 24,739 (38\%) & 28,885 (39\%) \\
\hline \multicolumn{4}{|l|}{ Antibiotics } \\
\hline -Former use & 2,415 (25\%) & $15,589(24 \%)$ & $18,004(24 \%)$ \\
\hline -Current use & 2,623 (27 \%) & $14,904(23 \%)$ & $17,527(23 \%)$ \\
\hline \multicolumn{4}{|l|}{ Operation year } \\
\hline 2005-2006 & 1,339 (14\%) & $11,114(17 \%)$ & $12,453(17 \%)$ \\
\hline 2007-2008 & 1,482 (15\%) & $11,754(18 \%)$ & $13,236(18 \%)$ \\
\hline 2009-2010 & $1,679(17 \%)$ & 11,045 (17\%) & $12,724(17 \%)$ \\
\hline 2011-2012 & 1,690 (18\%) & $11,016(17 \%)$ & $12,706(17 \%)$ \\
\hline 2013-2014 & 1,771 (19\%) & $10,514(16 \%)$ & 12,285 (16\%) \\
\hline 2015-2016 & 1,631 (17\%) & 9,736 (15\%) & 11,367 (15\%) \\
\hline \multicolumn{4}{|l|}{ Body Mass Index, kg/m2 } \\
\hline Underweight $<18.5$ & $903(9 \%)$ & $5,551(9 \%)$ & 6,454 (9\%) \\
\hline Normal weight 18.5- 24.9 & $4,244(44 \%)$ & 29,737 (46\%) & $33,981(45 \%)$ \\
\hline Overweight 25-29.9 & 1,782 (19\%) & 12,906 (20\%) & $14,688(20 \%)$ \\
\hline Obese $\geq 30$ & $565(6 \%)$ & 3,538 (5\%) & 4,103 (5\%) \\
\hline Unknown & $2,098(22 \%)$ & 13,447 (21\%) & $15,545(21 \%)$ \\
\hline \multicolumn{4}{|l|}{ Specific comorbidities (yes) } \\
\hline Peripheral vascular disease & $926(10 \%)$ & $60,186(92 \%)$ & $5,919(8 \%)$ \\
\hline Cerebrovascular disease & 2,055 (21\%) & $11,720(18 \%)$ & 13,775 (18\%) \\
\hline Chronic pulmonary disease & 1,798 (19\%) & 7,530 (12\%) & $9,328(12 \%)$ \\
\hline Diabetes type 1 and 2 & $1,016(11 \%)$ & $5,378(8 \%)$ & 6,394 (9\%) \\
\hline Any tumor & $1,453(15 \%)$ & $9,504(15 \%)$ & 10,957 (15\%) \\
\hline
\end{tabular}

Table 1: Baseline characteristics of the hip fracture cohort patients, with or without infection 30 days after surgery, Denmark, 2005-2016 


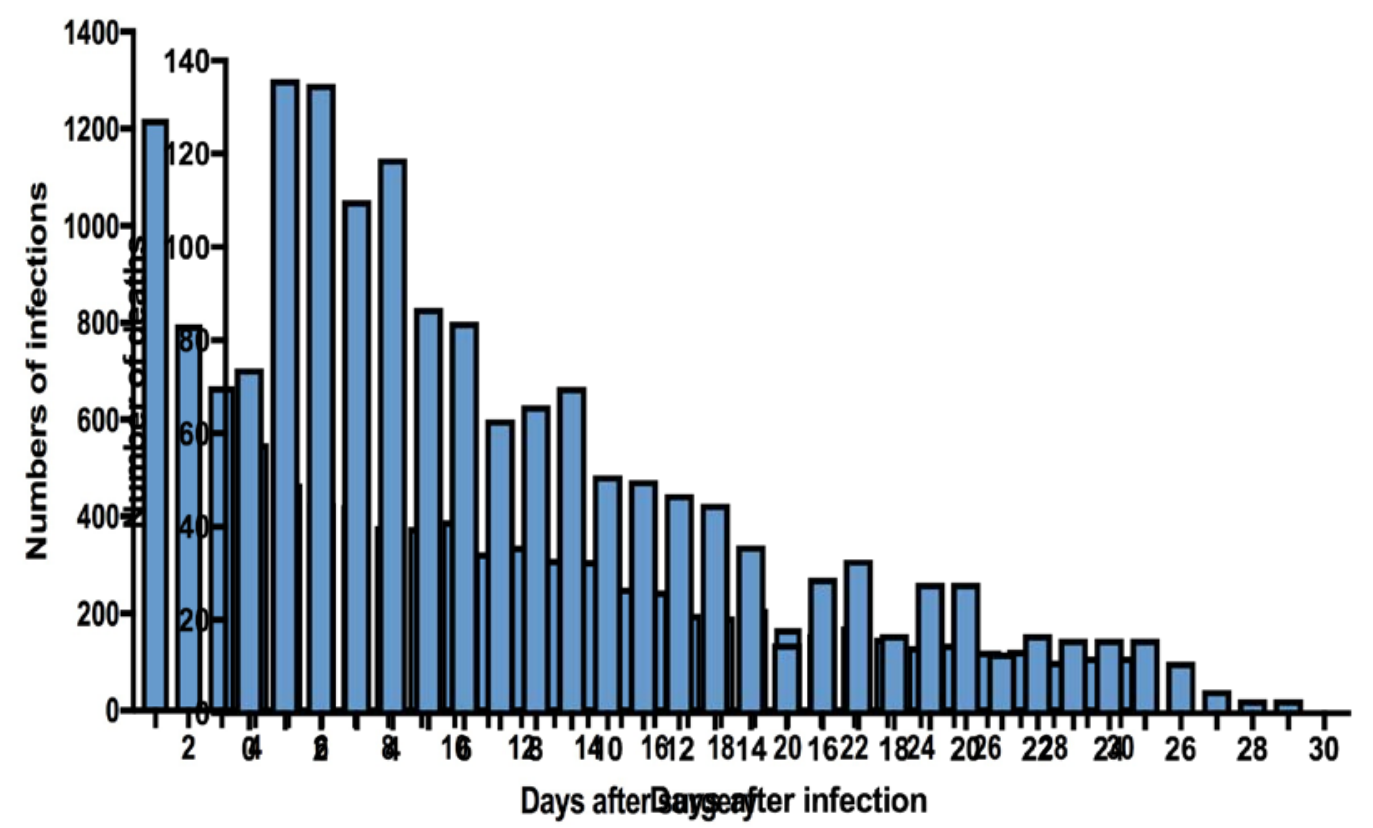

\section{Figure 1A and 1B:}

1A: Frequency of postoperative infection within 30 days, divided by the exact day of infection after hip fracture surgery
1B: Numbers of deaths within infected patients,

divided by the exact day of death after postoperative infection 


\subsection{Mortality in infected vs. non-infected patients}

A total of 1,443 of 9,592 (15\%) infected patients died within 30 days of hip fracture surgery. Patients who sustained any infection within 30 days of hip fracture surgery were more likely to die during the follow-up period of 30 days than those with absence of infection. Unadjusted mortality rates (MR) were 8.43 (95 \% CI: 8.00-8.88) by 1,000 person-years for infected patient, and 3.34 (95 \% CI: 3.26-3.43) for non-infected patients, corresponding to an aHR of 2.72 (95 \% CI: 2.56-2.88) (Table 2). The 30-days mortality risk was over 4-fold higher for patients who sustained pneumonia compared to non-pneumonia patients [aHR: 4.18 (95 \% CI: 3.91-4.48)]. Patients with systemic sepsis were associated with the highest risk of 30-days mortality in our study, corresponding to aHR of 8.86 (95 \% CI: 7.88-9.95) compared to non-systemic sepsis patients. The aHR for patients who underwent reoperation due to infection was 2.95 (95 \% CI: 1.88-4.64) compared to patients without reoperation due to infection. In contrast, sustaining UTIs was associated with lower mortality risk [aHR: 0.69 (95 \% CI: 0.60-.0.79)]. Table 2 shows numbers of infections and MRs for sepsis, pneumonia, UTIs and reoperation due to infection.

The sensitivity analysis adjusting for specific comorbidities instead of CCI-score did not substantially change our results. 


\section{Days Mortality Risk}

\begin{tabular}{|c|c|c|c|c|c|c|}
\hline $\begin{array}{l}\text { Postoperative } \\
\text { infection within } \\
30 \text { days after } \\
\text { surgery }\end{array}$ & $\begin{array}{l}\text { No. Of } \\
\text { Patients }\end{array}$ & $\begin{array}{l}\text { No. Of } \\
\text { Deaths }\end{array}$ & $\mathrm{PY}^{* *}$ & $\begin{array}{l}\text { Mortality Rate pr. } \\
1000 \text { PY (95 \% CI) }\end{array}$ & $\begin{array}{l}\text { Crude HR } \\
\text { (95\% CI) }\end{array}$ & $\begin{array}{l}\text { Adjusted HR } \\
(95 \% \mathrm{CI})^{* * *}\end{array}$ \\
\hline \multicolumn{7}{|l|}{ Any infection } \\
\hline Yes & 9,592 & 1,443 & 171156 & $8.43(8.00-8.88)$ & $3.20(3.02-3.40)$ & $2.72(2.56-2.88)$ \\
\hline No & 74,771 & 6.451 & 1928987 & $3.34(3.26-3.43)$ & Reference & Reference \\
\hline \multicolumn{7}{|l|}{ Pneumonia } \\
\hline Yes & 3,938 & 969 & 65351 & $14.83(13.92-15.79)$ & 5.41 (5.05-5.79) & $4.18(3.91-4.48)$ \\
\hline No & 74,771 & 6,925 & 2034792 & $3.40(3.32-3.48)$ & Reference & Reference \\
\hline \multicolumn{7}{|l|}{ Sepsis } \\
\hline Yes & 761 & 300 & 9052 & 33.14 (29.60-37.11) & $11.29(10.05-12.68)$ & $8.86(7.88-9.95)$ \\
\hline No & 74,771 & 7,594 & 2091091 & $3.63(3.56-3.71)$ & Reference & Reference \\
\hline \multicolumn{7}{|l|}{$\begin{array}{l}\text { Reoperation due } \\
\text { to Infection }\end{array}$} \\
\hline Yes & 261 & 19 & 2561 & $7.50(4.78-11.76)$ & $3.00(1.91-4.72)$ & $2.95(1.88-4.64)$ \\
\hline No & 74,771 & 7,875 & 2097582 & $3.75(3.67-3.84)$ & Reference & Reference \\
\hline \multicolumn{7}{|l|}{$\begin{array}{l}\text { Urinary tract } \\
\text { infections }\end{array}$} \\
\hline Yes & 4,328 & 213 & 87430 & $2.44(2.13-2.79)$ & $0.76(0.67-0.88)$ & $0.69(0.60-0.79)$ \\
\hline No & 74,771 & 7681 & 2012713 & $3.82(3.73-3.90)$ & Reference & Reference \\
\hline
\end{tabular}

Table 2: Mortality risk and Hazard Ratio (HR) following infection* within 30 days after hip fracture surgery

\footnotetext{
* Infection was treated as time-varying exposure. **Person-Years (PY) *** Hazard ratios were adjusted for sex, age, comorbidity level, alcohol-related diseases, marital status and medication use (antibiotics, corticosteroid, anticoagulants and SSRIs)
} 


\section{$\underline{\text { 3.3 Stratified analyses }}$}

The 30 days mortality risk was highly increased for any infection, systemic sepsis, pneumonia, and reoperation due to infection irrespective of sex, age, and CCI-score (Figure 2, 3, 4, and Supplementary Figure 2). Age $\geq 85$, high comorbidity and males, had the highest MR among the infected patients. However, the aHR was 2-4 times higher for any infected patients in all groups. For pneumonia, aHR was 5.30 (95 \% CI: 4.63-6.07) among patients with no comorbidities, and 3.40 (95 \% CI: 3.00-3.87) among patients with high comorbidity level. Systemic sepsis was associated with an aHR of 12.75 (95 \% CI: 10.05-16.17) among patients with no comorbidities, and 7.32 (95 \% CI: 5.97-8.96) among patients with high comorbidity level. In addition, we observed gender differences in the association between mortality and systemic sepsis, where females had an aHR mortality of 13.14 (95 \% CI: 11.21-15.40), and males had an aHR of 6.63 (95 \% CI: 5.58-7.87), following systemic sepsis. 


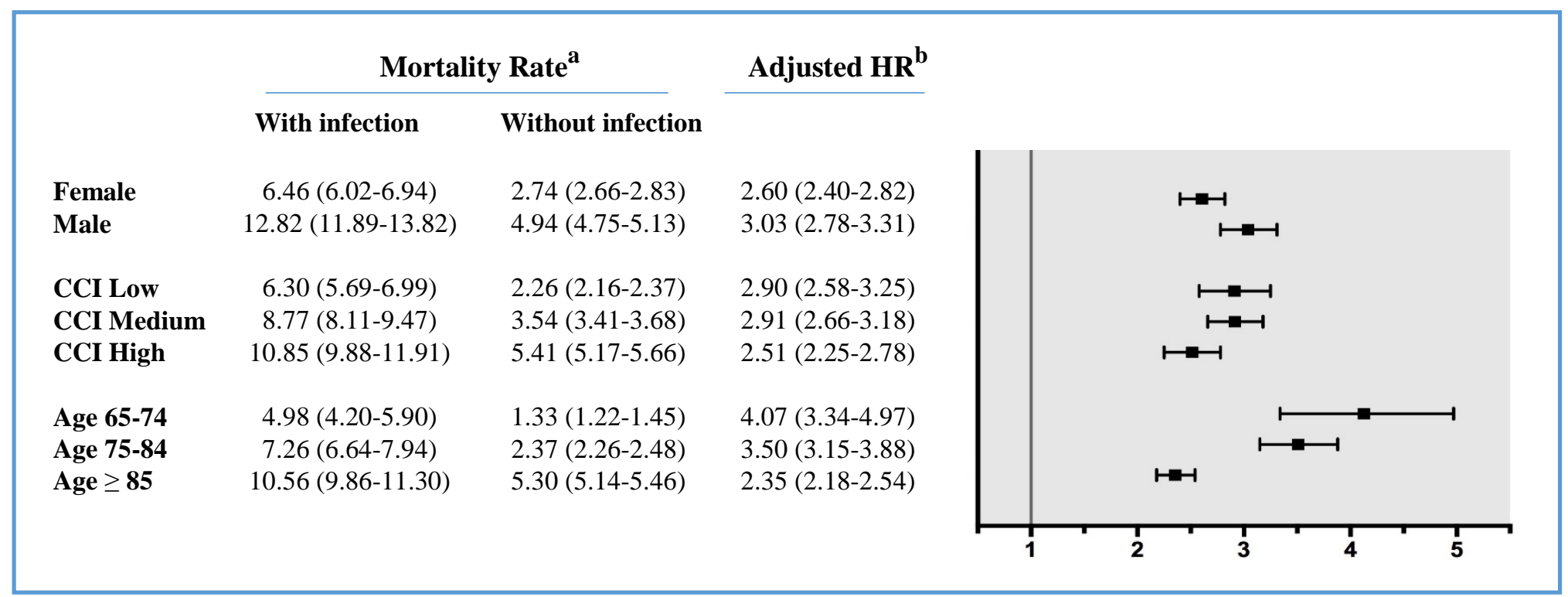

Figure 2: Association between any infection* and mortality 0-30 days after hip fracture, stratified by sex, Charlson Comorbidity Index-score and age, Denmark 2005-2016

* Infection was treated as time-varying exposure. ${ }^{\mathrm{a}}$ : Per 1000 person-years (with corresponding $95 \%$ CI) ${ }^{\text {b}}$ : Hazard ratios were adjusted for sex, age, and comorbidity level, without the stratifying variable (with corresponding $95 \% \mathrm{CI}$ ) 


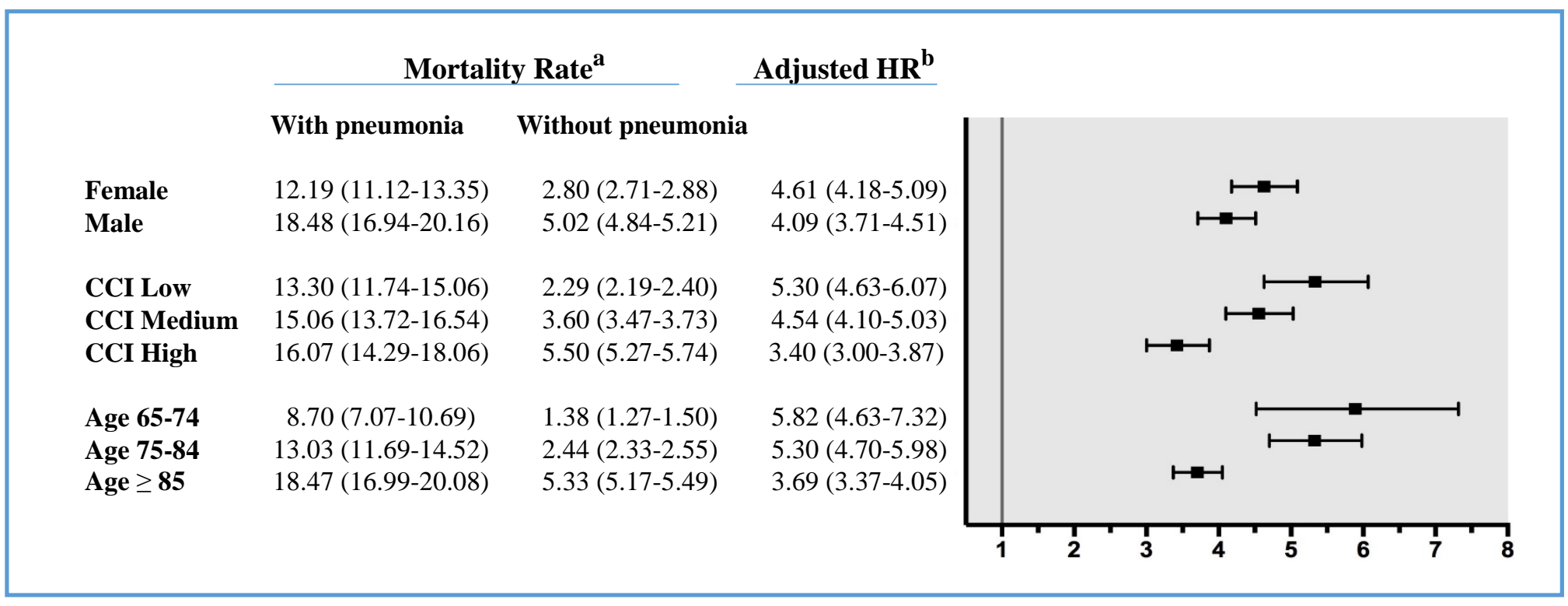

Figure 3: Association between pneumonia* and mortality 0-30 days after hip fracture surgery, stratified by sex, Charlson Comorbidity Index-score and age, Denmark 2005-2016

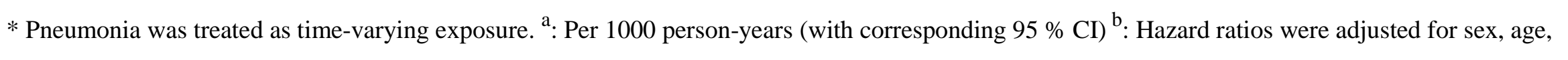
and comorbidity level, without the stratifying variable (with corresponding $95 \% \mathrm{CI}$ ) 


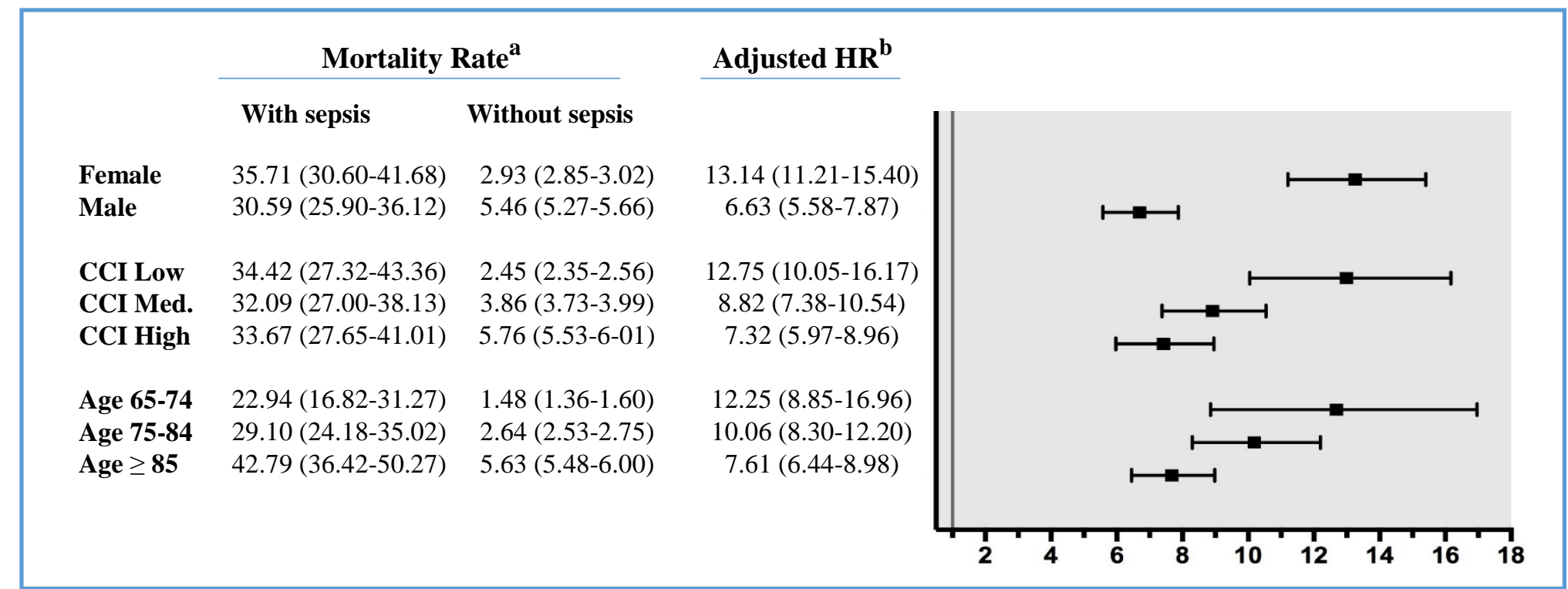

Figure 4: Association between systemic sepsis* and mortality 0-30 days after hip fracture surgery, stratified by sex, Charlson Comorbidity Index-score CI-score and age, Denmark 2005-2016

* Systemic sepsis was treated as time-varying exposure. ${ }^{a}$ : Per 1000 person-years (with corresponding $95 \%$ CI) ${ }^{\text {b}}$ : Hazard ratios were adjusted for sex, age, and comorbidity level, without the stratifying variable (with corresponding $95 \% \mathrm{CI}$ ) 


\section{Discussion}

This population-based cohort study indicates excessive risk of 30-days mortality among hip fracture patients following any postoperative infection, in particularly after systemic sepsis, pneumonia, and reoperation due to infection. The mortality was increased regardless of patients’ age, sex, and comorbidity.

To the best of our knowledge, this is the largest conducted study demonstrating the association between infection and mortality after hip fracture surgery. We extended existing knowledge evaluating the mortality following any postoperative infection, instead of just specific types of infections. We provided further evidence on increased mortality after infection by stratifying on age, sex, and comorbidity.

Our study supports previous findings of elevated mortality after pneumonia, sepsis, and surgical site infection within 30 days after hip fracture surgery.[3, 10-13] However, both Roche et al.,[3] and Lv et al.,[11] found approximately 3 times higher mortality after postoperative pneumonia (resulting in a 30-days mortality of 27-43 \%), whereas we demonstrated over 4 times higher mortality risk. Moreover, we found a higher mortality following sepsis compared to those reported from Bohl. et al.[adjusted RR: 4.4 (95 \% CI: 3.7-5.4)].[12] This disparity might potentially be explained by immortal time bias in previous studies, as we were the only study using time-varying exposure in order to avoid a potential underestimation of the association. However, changes could also be related to differences in exposure time and it's definition, different use of adjusted variables, or the differences in characteristics of the study populations and sample size.

Male, high age, and comorbidities are associated with higher mortality following hip fracture surgery in general,[2, 3, 5] corresponding to our mortality rates among infected patients as well. However, we observed that the relative mortality increased irrespective of age, sex, and comorbidity, and some types of the infection even had a higher increase among patients without 
comorbidities, and at lowest age. Thus, our findings suggest that infections not only increase mortality among the most vulnerable patients, but also have an even larger impact on the most "healthy" patients. This is probably due to a higher mortality rate among older and more comorbid patient in general, so sustaining an infection has less influence compared to the younger and more "healthy” patients.

Furthermore, we found a much higher mortality after systemic sepsis among females compared to males, resulting in a slightly higher mortality rate among females compared to males following systemic sepsis. This might suggest that sepsis could contribute to a gender difference within 30days mortality. Wehren et al.,[22] has previous suggested that infection could play part as one of the explanation of the gender differences in 1-year mortality. However, the underlying mechanisms regarding this are not fully understood.

In contrast to other infections, we found a reduced mortality following UTIs after hip fracture surgery. Interestingly, Roche et al. also demonstrated reduced 30-days mortality after UTIs [aHR: 0.6 (95 \% CI: 0.3-1.4)][3]. Our results regarding UTI should be interpreted with caution. UTI diagnosis is in particular risk for being underreported because the diagnosis does not provide reimbursement for department. Thus, our results could be due to chance alone. It is further likely that many patients already have UTI before being hospitalized for hip fracture, and detection and treatment for UTI during hospitalization and afterword would increase prognosis of patients.

\section{$\underline{4.1 \text { Methodological considerations }}$}

The major strengths of this study is based on the population-based design, including the large sample size and prospective collected individual-level data from medical databases. We detected hip fracture surgery from DMHFR, which has mandatory registration and a measured completeness of $99 \%$ up to 2008.[18] The validity of hip fracture codes in medical registries is generally 
high.[23] Furthermore, we have almost complete follow-up, with low risk of selection bias. We adjusted for many different confounders, including medication use. We used CCI, a highly implemented index score,[21] in order to control for comorbidity. The positive predictive value (PPV) of the comorbidity codes from DNPR has consistently very high accuracy.[24] In addition, we collected information on infections based on ICD-10 codes in the DNPR, and a high accuracy of these codes is previous indicated (the PPV of any infection diagnosis was $98 \%$ among cancer patients during 2006-2010).[25] Finally, our study avoids potential immortal bias by using novel method of time-varying exposure (See Supplementary Figure 1). To our knowledge, this is the first study to evaluate the association between mortality and infection after hip fracture surgery fully without a potential immortal bias.

However, our study includes some limitations. We were not able to adjust for socioeconomic status or life style factors. Anyhow, we adjusted for alcohol-related comorbidities, comorbidities related to smoking (Chronic Obstructive Pulmonal Disease (COPD)), and marital status to diminish the potential bias. In addition, we adjusted for all the 19 comorbidities included in CCI regardless of type of infection, and did not take into account that some comorbidities could be more important than others for some specific infections (for example COPD and pneumonia). Furthermore, we did not have any information on psychiatric comorbidities or comorbidities treated by general practitioners (GPs), and our study could be affected by residual confounding. Our results regarding sepsis and reoperation due to infection has lower power, especially in the stratified analysis. An additional limitation comprehend that the sensitivity of infection codes in DNPR is unknown, and infections are probably underreported. Even so, since the mortality outcome is unknown at the time of the infection registration, the potential misclassification is most likely non-differentiated, and could only underestimate the results. 


\subsection{Possible explanations and clinical perspectives}

There are mainly multiple factors contributing to high mortality after postoperative infection among hip fracture patients. These patients have high age, and are presented with multimorbidity and polypharmacy. Age-related changes involves a dysregulation in the immune system, known as immunosenescence.[26] In addition, infections in elderly might be overlooked. Even with a severe infection, typical symptoms like fever, might not be presence in elderly.[27, 28] The lack of symptoms may lead to delayed diagnosis and therapy, potentially contributing to increased mortality among the infected patients.[27, 29]

Our findings suggest that preventing any infection would be beneficial in order to reduce the 30-days mortality after hip fracture surgery. Early remobilization, respiratory exercises, and nutritional support could potentially avert some types of postoperative infections.[30, 31] Systemic prophylactic antibiotics in hip fracture surgery is well-recommended,[32, 33] but doses, durations, and combinations might be optimized. Furthermore, the rehabilitation of the patients immediately after discharge, including resources in municipalities, as well as collaboration with GPs, is presumably highly important for the prognosis following postoperative infections.

In conclusion, this population-based study provides evidence of substantially increased 30-days mortality risk following any postoperative infection, after hip fracture surgery. The risk increased particularly after systemic sepsis, pneumonia, and reoperation due to infection. 


\section{Acknowledgments:}

Study design: ABP, DPA and KEK. Study conduct: ABP and KEK. Data collection: NK Data analysis: KEK. Data interpretation: KEK, SJ, DPA and ABP. Drafting manuscript: KEK. Revising manuscript content: ABP, DPA, SJ, NK. Approving final version of manuscript: KEK, SJ, NK, DPA, ABP. ABP and KEK takes responsibility for the integrity of the data analysis.

Funding: Danmarks Frie Forskningsråd and Department of Clinical Epidemiology Research Fondation supported the study. The funding source had no role in the study design; in the collection, analysis, or interpretation of the data; in the writing of this paper; or in the decision to submit the paper for publication.

\section{Competing interests:}

Kaja E. Kjørholt, Søren P. Johnsen, Nickolaj R. Kristensen and Alma B. Pedersen declare that they have no conflict of interest.

Daniel Prieto-Alhambra’s department has received unrelated industry funding in the forms of: 1.research grants from Amgen and UCB Biopharma; 2.consultancy fees from UCB; and speaker fees from Amgen. 


\section{References}

1. Kanis JA, Odén A, McCloskey E V., et al. A systematic review of hip fracture incidence and probability of fracture worldwide. Osteoporos Int. 2012 Sep 15;23(9):2239-56.

2. Abrahamsen B, van Staa T, Ariely R, et al. Excess mortality following hip fracture: a systematic epidemiological review. Osteoporos Int. 2009 Oct 7;20(10):1633-50.

3. Roche JJW, Wenn RT, Sahota O, et al. Effect of comorbidities and postoperative complications on mortality after hip fracture in elderly people: prospective observational cohort study. BMJ Br Med J. 2005;331(7529):1374.

4. Nielsen KA, Jensen NC, Jensen CM, et al. Quality of care and 30 day mortality among patients with hip fractures: a nationwide cohort study. BMC Health Serv Res. 2009 Dec 12;9(1):186.

5. de Luise C, Brimacombe M, Pedersen L, et al. Comorbidity and mortality following hip fracture: a population-based cohort study. Aging Clin Exp Res. 2008 Oct;20(5):412-8.

6. Lawrence VA, Hilsenbeck SG, Noveck H, et al. Medical Complications and Outcomes After Hip Fracture Repair. Arch Intern Med. 2002 Oct 14;162(18):2053.

7. Pedersen AB, Christiansen CF, Gammelager H, et al. Risk of acute renal failure and mortality after surgery for a fracture of the hip: A population-based cohort study. Bone Joint J.2016 Aug 1;98-B(8):1112-8.

8. Kjørholt KE, Johnsen SP, Kristensen NR, et al. Increasing Risk of Hospital-Treated Infections and Community-Based Antibiotic Use After Hip Fracture Surgery: A Nationwide Study 2005-2016. J Bone Miner Res. 2018 Dec 4;

9. Chatterton BD, Moores TS, Ahmad S, et al. Cause of death and factors associated with early in-hospital mortality after hip fracture. Bone Joint J. 2015 Feb;97-B(2):246-51.

10. Bohl DD, Sershon RA, Saltzman BM, et al. Incidence, Risk Factors, and Clinical Implications of Pneumonia After Surgery for Geriatric Hip Fracture. J Arthroplasty. 2018 May1;33(5):1552-1556.e1.

11. Lv H, Yin P, Long A, et al. Clinical characteristics and risk factors of postoperative 
pneumonia after hip fracture surgery: a prospective cohort study. Osteoporos Int. 2016 Oct 30;27(10):3001-9.

12. Bohl DD, Iantorno SE, Saltzman BM, et al. Sepsis Within 30 Days of Geriatric Hip Fracture Surgery. J Arthroplasty. 2017 Oct;32(10):3114-9.

13. Duckworth AD, Phillips S-A, Stone O, et al. Deep infection after hip fracture surgery: Predictors of early mortality. Injury. 2012 Jul;43(7):1182-6.

14. Jones M, Fowler R. Immortal time bias in observational studies of time-to-event outcomes. $J$ Crit Care. 2016 Dec 1;36:195-9.

15. Suissa S. Immortal time bias in observational studies of drug effects. Pharmacoepidemiol Drug Saf. 2007 Mar;16(3):241-9.

16. Ventola CL. The antibiotic resistance crisis: part 1: causes and threats. P T. 2015 Apr;40(4):277-83.

17. Schmidt M, Pedersen L, Sørensen HT. The Danish Civil Registration System as a tool in epidemiology. Eur J Epidemiol. 2014 Aug 26;29(8):541-9.

18. Danish Multidiciplinary Hip Fracture Registry [Internet]. Available from: http://www.rkkp.dk/om-rkkp/de-kliniske-kvalitetsdatabaser/hoftenaere-laerbensbrud/

19. Schmidt M, Schmidt SAJ, Sandegaard JL, et al. The Danish National Patient Registry: a review of content, data quality, and research potential. Clin Epidemiol. 2015 Nov;7:449.

20. Johannesdottir SA, Horváth-Puhó E, Ehrenstein V, et al.Existing data sources for clinical epidemiology: The Danish National Database of Reimbursed Prescriptions. Clin Epidemiol. 2012 Nov;303.

21. D’Hoore W, Sicotte C, Tilquin C. Risk adjustment in outcome assessment: the Charlson comorbidity index. Methods Inf Med.1993 Nov;32(5):382-7.

22. Wehren LE, Hawkes WG, Orwig DL, et al. Gender differences in mortality after hip fracture: the role of infection. J Bone Miner Res. 2003 Dec;18(12):2231-7.

23. Hudson M, Avina-Zubieta A, Lacaille D, et al. The validity of administrative data to identify hip fractures is high—a systematic review. J Clin Epidemiol. 2013 Mar 1;66(3):278-85. 
24. Thygesen SK, Christiansen CF, Christensen S, et al. The predictive value of ICD-10 diagnostic coding used to assess Charlson comorbidity index conditions in the populationbased Danish National Registry of Patients. BMC Med Res Methodol. 2011 May 28;11(1):83.

25. Holland-Bill L, Xu H, Sørensen HT, et al. Positive predictive value of primary inpatient discharge diagnoses of infection among cancer patients in the Danish National Registry of Patients. Ann Epidemiol. 2014 Aug;24(8):593-597.e18.

26. Weiskopf D, Weinberger B, Grubeck-Loebenstein B. The aging of the immune system. Transpl Int. 2009 Nov;22(11):1041-50.

27. Crossley KB, Peterson PK. Infections in the Elderly. Vol. 22, Clinical Infectious Diseases. Oxford University Press;. p. 209-14.

28. Clifford KM, Dy-Boarman EA, Haase KK, et al. Challenges with Diagnosing and Managing Sepsis in Older Adults. Expert Rev Anti Infect Ther. 2016 ;14(2):231-41.

29. Liu VX, Fielding-Singh V, Greene JD, et al. The Timing of Early Antibiotics and Hospital Mortality in Sepsis. Am J Respir Crit Care Med. 2017 Oct 29;196(7):856-63.

30. Dovjak P, Iglseder B, Mikosch P, et al. Treatment and prevention of postoperative complications in hip fracture patients: infections and delirium. Wiener Medizinische Wochenschrift. 2013 Oct 15;163(19-20):448-54.

31. Avenell A, Smith TO, Curtain JP, et al. Nutritional supplementation for hip fracture aftercare in older people. Cochrane Database Syst Rev. 2016 Nov 30; Available from:

32. Gillespie WJ, Walenkamp GH. Antibiotic prophylaxis for surgery for proximal femoral and other closed long bone fractures. In: Gillespie WJ, editor. Cochrane Database of Systematic Reviews. Chichester, UK: John Wiley \& Sons, Ltd; 2010. p. CD000244.

33. Southwell-Keely, J. P. et al. Antibiotic prophylaxis in hip fracture surgery: a metaanalysis. Clin. Orthop. Relat. Res. 179-84 (2004). 